\title{
Benchmarking in vitro tissue-engineered blood-brain barrier models
}

\author{
Jackson G. DeStefano ${ }^{1,2+}$, John J. Jamieson ${ }^{1,3+}{ }^{\text {, Raleigh M. Linville }}{ }^{1,4+}$ and Peter C. Searson ${ }^{1,2,5^{*}}$ (0)
}

\begin{abstract}
The blood-brain barrier (BBB) plays a key role in regulating transport into and out of the brain. With increasing interest in the role of the BBB in health and disease, there have been significant advances in the development of in vitro models. The value of these models to the research community is critically dependent on recapitulating characteristics of the BBB in humans or animal models. However, benchmarking in vitro models is surprisingly difficult since much of our knowledge of the structure and function of the BBB comes from in vitro studies. Here we describe a set of parameters that we consider a starting point for benchmarking and validation. These parameters are associated with structure (ultrastructure, wall shear stress, geometry), microenvironment (basement membrane and extracellular matrix), barrier function (transendothelial electrical resistance, permeability, efflux transport), cell function (expression of BBB markers, turnover), and co-culture with other cell types (astrocytes and pericytes). In suggesting benchmarks, we rely primarily on imaging or direct measurements in humans and animal models.
\end{abstract}

Keywords: Blood-brain barrier, Tissue-engineering, Induced pluripotent stem cells, Benchmarking, In vitro modeling, Brain microvascular endothelial cells

\section{Introduction}

Recent advances in stem cell technology, tissue engineering, and microfluidics have led to rapid advances in the complexity of in vitro models of the blood-brain barrier (BBB). Stem cell technology provides a reliable source of human, brain-specific cells: iPSC-derived human brain microvascular endothelial cells (dhBMECs) exhibit many of the hallmarks of human BMECs [1-29], a long-standing problem in developing BBB models [30-32]. Additionally, protocols for iPSC-derived astrocytes, pericytes, microglia and neurons have been developed to facilitate modeling of the neurovascular unit [33]. Similarly, advances in tissue engineering and microfluidics provide the tools for organization of perfusable microvessels or microvascular networks [34, 35]. Diverse BBB-on-a-chip models have emerged over the last 5 years, they can generally be classified as: (1) two-dimensional microfluidic

\footnotetext{
*Correspondence: searson@jhu.edu

${ }^{\dagger} J a c k s o n$ G. DeStefano, John J. Jamieson and Raleigh M. Linville contributed equally to this work

${ }^{5} 120$ Croft Hall, Johns Hopkins University, 3400 North Charles Street, Baltimore, MD 21218, USA

Full list of author information is available at the end of the article
}

models, (2) hybrid microfluidic models, (3) three-dimensional templated models or (4) self-organization models. Two-dimensional microfluidic models incorporating a permeable membrane (resembling that of a traditional Transwell ${ }^{\circledR}$ assay) are extremely valuable for applications such as drug screening or measures of electrical resistance, however, these models do not recapitulate many aspects of physiological BBB function [36-39]. Hybrid microfluidic models capture more complexity but lack homogenous cell-ECM interactions and cylindrical geometry and are thus not able to respond to vasodilation/constriction [40, 41]. Templating approaches support generation of singular cylindrical microvessels embedded within an extracellular matrix that can be integrated into a flow system for live-cell imaging $[23,24,42-44]$. Lastly, self-organization approaches that mimic vasculogenesis and/or angiogenesis have emerged to generate multicellular models of brain microvascular networks $[45,46]$. Since animal models do not always recapitulate human physiology or disease [47, 48], in vitro models can provide an important link between human physiology and animal models.

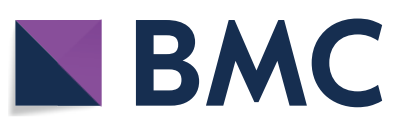

(c) The Author(s) 2018. This article is distributed under the terms of the Creative Commons Attribution 4.0 International License (http://creativecommons.org/licenses/by/4.0/), which permits unrestricted use, distribution, and reproduction in any medium, provided you give appropriate credit to the original author(s) and the source, provide a link to the Creative Commons license, and indicate if changes were made. The Creative Commons Public Domain Dedication waiver (http://creativecommons.org/ publicdomain/zero/1.0/) applies to the data made available in this article, unless otherwise stated. 
The value of $\mathrm{BBB}$ models in basic and translational research is dependent on the ability to recapitulate in vivo and ex vivo studies. The fidelity of the model is usually dictated by the purpose and the processes under study. More reductive models will naturally recapitulate fewer characteristics of the BBB, while more complex models attempt to recapitulate more characteristics but are usually lower throughput. In all cases, benchmarking to in vivo studies is key to establishing physiological relevance.

Benchmarking is surprisingly challenging, in large part because much of our knowledge about BBB structure and function is derived from in vitro studies. Here we describe 12 design criteria for tissue engineering the human BBB. This is not intended to be a complete checklist of benchmarks for model validation, but a limited set of parameters associated with structure (ultrastructure, wall shear stress, geometry), microenvironment (basement membrane and extracellular matrix), barrier function [transendothelial electrical resistance (TEER), permeability, efflux transport], cell function (expression of BBB markers, turnover), and co-culture with other cell types (astrocytes and pericytes). Depending on the purpose of the model, the specific benchmarks may vary and may not include all those listed here. Wherever possible, benchmarks are suggested based on imaging or direct measurement in humans or animal models.

\section{Benchmarks for blood-brain barrier models Ultrastructure}

To power the adult human brain, nutrients are supplied to the 100 billion neurons via a $600 \mathrm{~km}$ network of capillaries and microvessels [49]. Since the brain does not have significant capacity to store metabolic nutrients, cerebral blood flow is proportional to cerebral metabolic rate [50], and the cell bodies of neurons are typically $10-20 \mu \mathrm{m}$ from the nearest capillary [51, 52]. Capillaries are supplied by arterioles and drained by post-capillary venules which are up to $100-200 \mu \mathrm{m}$ in diameter. Capillaries in the human brain are $8-10 \mu \mathrm{m}$ in diameter, with 50-100 $\mu \mathrm{m}$ long segments between bifurcations (Fig. 1A, B) [53-56]. In contrast, the smallest capillaries in the mouse brain are around $3 \mu \mathrm{m}$ in diameter, and in the rat brain are around $4 \mu \mathrm{m}$ in diameter [57]. In capillaries, BMECs wrap around to form junctions with themselves and their upstream and downstream neighbors (Fig. 1C, D). The spatial arrangement of pericytes and astrocytes are described in subsequent sections. Post-capillary venules (PCVs) are characterized by a perivascular space with limited supporting cells [58-60]. Evidence suggests that extravasation of leukocytes, tumor cells, and parasites occurs preferentially at PCVs [60-66].
Electron microscopy (EM) images of the ultrastructure of microvessels and capillaries in rodent brains show BMECs are relatively flat and have considerable cell-cell overlap (typically $0.5 \mu \mathrm{m}$ or more) (Fig. 1C), likely associated with tight junction formation [67-71]. In EM images of the overlapping regions using freeze-fracture, tight junctions appear as a network of contact points or particles between the extracellular domains of claudin-5, occludin and other transmembrane proteins on opposing membranes (Fig. 1E) [72, 73].

In establishing BBB models, desired geometry is dictated by the diameter and location of the target microvessel (arteriole, capillary, or venule), which also determines other aspects of the local microenvironment (discussed in subsequent sections).

\section{Wall shear stress}

Wall shear stress is thought to regulate many processes associated with the endothelium [76-79], however, much of our knowledge comes from in vitro experiments where the characteristics of the BMECs and the 2D geometry may influence results. Nonetheless, shear stress can play a role in mediating processes such as leukocyte adhesion, where the probability of capture is higher in postcapillary venules where the shear stress is relatively low. In 3D models, wall shear stress can be determined from particle image velocimetry (PIV) via analysis of fluorescent beads in the perfusion media or by calculating flow rate. These methods supports determination of the flow profile and wall shear stress within a microfluidic device or tissue-engineered microvessel [76, 77, 80]. Wall shear stress can also be estimated from the velocity of red blood cells (RBCs) which enables correlation with in vivo experiments.

In the arterial tree, the wall shear stress is $10-70$ dyne $\mathrm{cm}^{-2}$ depending on vessel diameter [81, 82]. Fluctuations in blood pressure during the cardiac cycle, typically oscillating between 80 and $120 \mathrm{mmHg}$, lead to pulsatile arterial blood flow [83]. These fluctuations are damped as the vessel diameter decreases, resulting in near constant blood flow in small arterioles, capillaries and venules. RBC velocity in brain capillaries in rodent models is in the range of $0.5-2.0 \mathrm{~mm} \mathrm{~s}^{-1}$ [84-91], corresponding to a wall shear stress of about 20-40 dyne $\mathrm{cm}^{-2}$ [92]. The large range of shear stress in capillaries is in part due to neurovascular coupling and the wide range of metabolic demands [93-98]. In mouse post-capillary venules (PCVs), the flow is highly damped with an average RBC velocity of $5-7 \mathrm{~mm} \mathrm{~s}^{-1}$ corresponding to an average wall shear stress of 1-4 dyne $\mathrm{cm}^{-2}[84,92,99-101]$. Erythrocyte velocity was used to estimate a mean wall shear stress of 1-6 dyne $\mathrm{cm}^{-2}$ in capillaries and PCVs ranging 

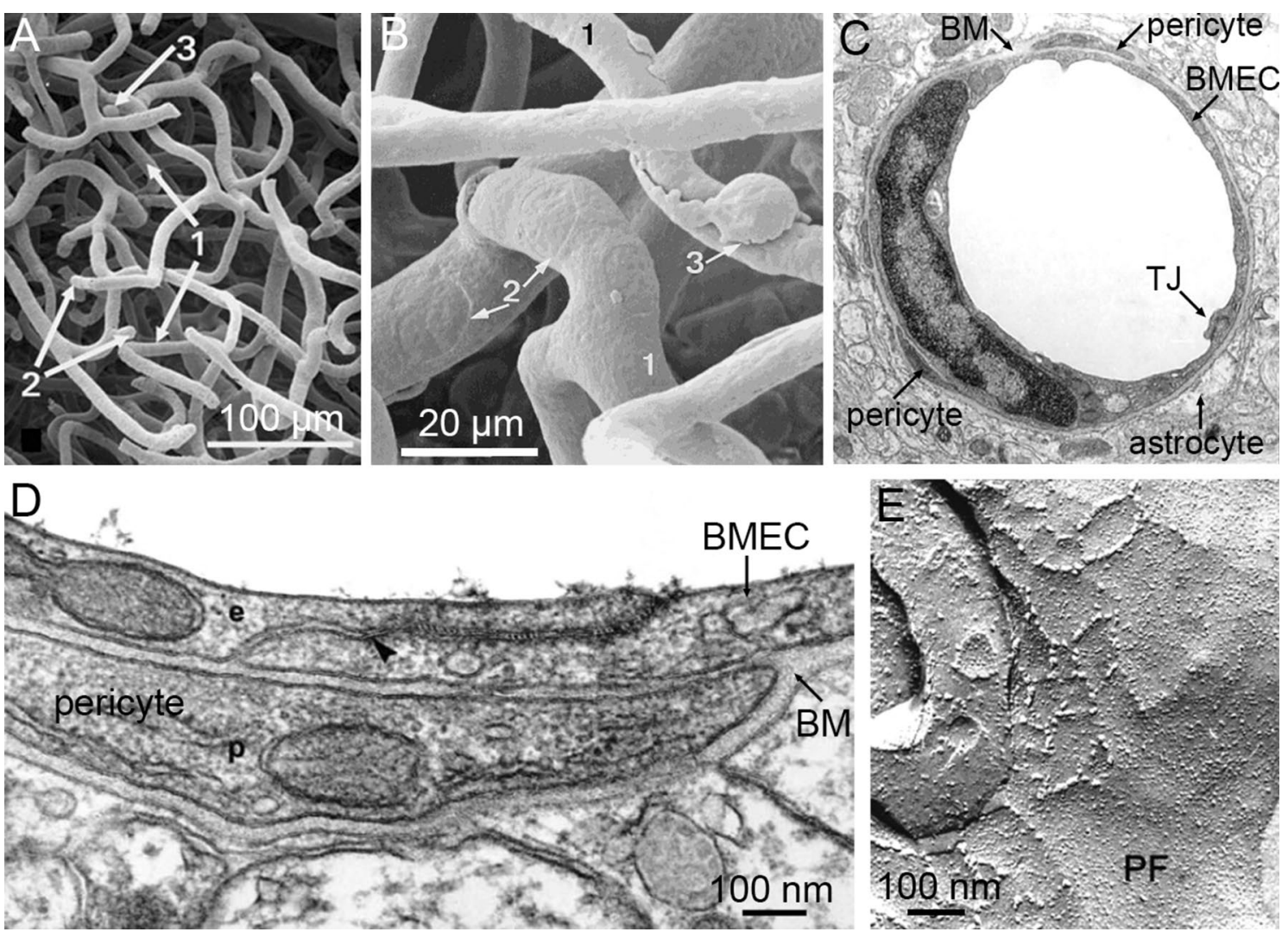

Fig. 1 EM images of brain microvessels. A Scanning electron micrograph of a replica of cortical capillaries in the frontal lobe of the human brain (from [74]). B Scanning electron micrograph of a replica of a cortical capillary network in the human brain showing the imprint of endothelial cell nuclei (2) and a pericyte with a "bump on a log" morphology (3) (from [74]). C Cross-section of a capillary in the frontoparietal cortex of a Wistar-Kyoto rat showing an endothelial cell wrapping around to form a tight junction with itself, along with associated pericytes and astrocyte end-feet (from [70]). D Transmission electron microscope cross-section of a cortical capillary in a rat. A systemically injected lanthanum compound penetrated the inter-endothelial space up to the tight junction (from [71]). E Freeze-fracture replicas of cerebral endothelial cell tight junctions. In capillary preparations, most P-face strands are occupied with particles (from [75])

in size from 4 to $20 \mu \mathrm{m}$ in the human bulbar conjunctiva [99].

In benchmarking in vitro models, the flow system should be designed to achieve the average wall shear stress of the microvessel type (arteriole, capillary, or venule). For the case of arterioles and capillaries, recapitulating pulsatile flow may also be important as it has been shown to influence barrier function, solute transport along the endothelium and inflammation within in vitro BBB models $[44,79,102]$.

\section{Cylindrical geometry}

The cylindrical geometry of microvessels imposes two important constraints on BMECs. First, cells experience curvature, which is inversely related to diameter, and plays a role in BMEC behavior. Human BMECs in confluent monolayers resist elongation and alignment due to curvature, whereas other ECs elongate and align to minimize the effects of curvature [103]. This may represent an evolutionary advantage by reducing the total length of cell-cell junctions per unit length of vessel, thereby reducing paracellular transport. Second, the cylindrical geometry means that there is a finite number of cells around the perimeter of a microvessel. In capillaries where BMECs wrap around and form tight junctions with themselves, there is one cell around the perimeter. In microvessels there are relatively few cells around the perimeter and hence cell-cell interactions and processes such as motility are extremely limited in comparison to 2D monolayers [24, 103]. Whether cylindrical geometry and shear stress are critical to achieve physiological barrier function is not well understood. However, permeabilities for Lucifer yellow in iPSC-derived human BMEC microvessels and in the Transwell ${ }^{\circledR}$ assay are similar [24], suggesting that physiological geometry and shear stress are not prerequisites for tight junction formation. 


\section{Basement membrane}

The basement membrane surrounding the endothelial cells in the cerebrovasculature consists of fibronectin, laminin, collagen type IV, heparan sulfate proteoglycans (HSPG) such as perlecan, and nidogens/entactins [57, 104-108]. The thickness (20-200 nm) and composition of the basement membrane is dependent on the location in the cerebrovasculature. In arteries and arterioles the presence of perivascular smooth muscle cells results in an inner endothelial basement membrane and an outer the parenchymal basement membrane, in which distinct laminin isoforms are present [109]. In capillaries, the basement membrane is relatively thin and occupies the space between the endothelial cells and astrocyte endfeet, and surrounds pericytes (see Fig. 1C, D) [71, 110]. In PCVs, the endothelial and parenchymal basement membrane are separated by the perivascular space. The basement membrane in capillaries is typically characterized by the presence of laminin $\alpha 4$ and $\alpha 5$. In tissueengineered models, basement membrane proteins can be deposited before cell seeding to promote adhesion of cells [23]; cells will then modify their local environment as they become established and secrete additional basement membrane proteins.

\section{Extracellular matrix (ECM)}

Selection of an extracellular matrix material is one of the major challenges in developing tissue-engineered models of the BBB since $70-85 \%$ of the brain volume is cells [111]. The extracellular space consists of a hyaluronic acid-based extracellular matrix and brain interstitial fluid. The extracellular space is characterized by an interconnected network of pores, $50-100 \mathrm{~nm}$ in size that serve as a reservoir for ions and a pathway for transport [111-114]. The extracellular volume fluctuates during normal brain function and decreases during development and aging $[111,115]$. The extracellular matrix in the interstitial space is composed of hyaluronic acid (HA), lecticans (aggrecan, versican, neurocan, and brevican), hyaluronan and proteoglycan link proteins (HAPLNs), and tenascins $[116,117]$. Common ECM proteins such as collagen type I and fibronectin are not present in the healthy brain [118]. As a result, tissue engineered models of the $\mathrm{BBB}$ must either incorporate large numbers of neurons and astrocytes, as well as other glial cells, or use a passive matrix material that provides structural support for BBB microvessels (see "Astrocyte" section for more details).

\section{Expression of BBB markers}

The expression of tight junctions (TJs) and transport systems are widely used to characterize in vitro BBB models [32]. Tight junctions between adjacent BMECs minimize paracellular permeability, maintain cell membrane polarization, and facilitate intracellular signaling [119]. Tight junctions are comprised of transmembrane proteins (i.e. occludin, claudins, junctional adhesion molecules) that interact with cytoplasmic scaffolding proteins (i.e. zona occludens), the actin cytoskeleton, and associated signaling proteins [120]. While many cell types express tight junctions, claudin-5 is endothelial-cell specific and particularly enriched in the brain cerebrovasculature compared to other TJ components [121, 122]. Localization of claudin-5, occludin, junctional adhesion molecules, and zona occludens- 1 are commonly used to validate cell sources for in vitro models [1, 2, 4, 19, 32, 123, 124]. Immunocytochemistry can be used to visualize these proteins at cell-cell junctions; importantly, TJ strands should be crisp (Fig. 2A, B), while under pathological or non-physiological conditions, they are non-continuous or show intracellular localization [7, 12, 14, 125].

Additionally, the brain endothelium is enriched in nutrient and efflux transporter systems. In the brain, Glucose transporter 1 (GLUT1) is highly expressed only in endothelial cells, and hence is a common biomarker for brain microvessels and capillaries (Fig. 2C). GLUT1
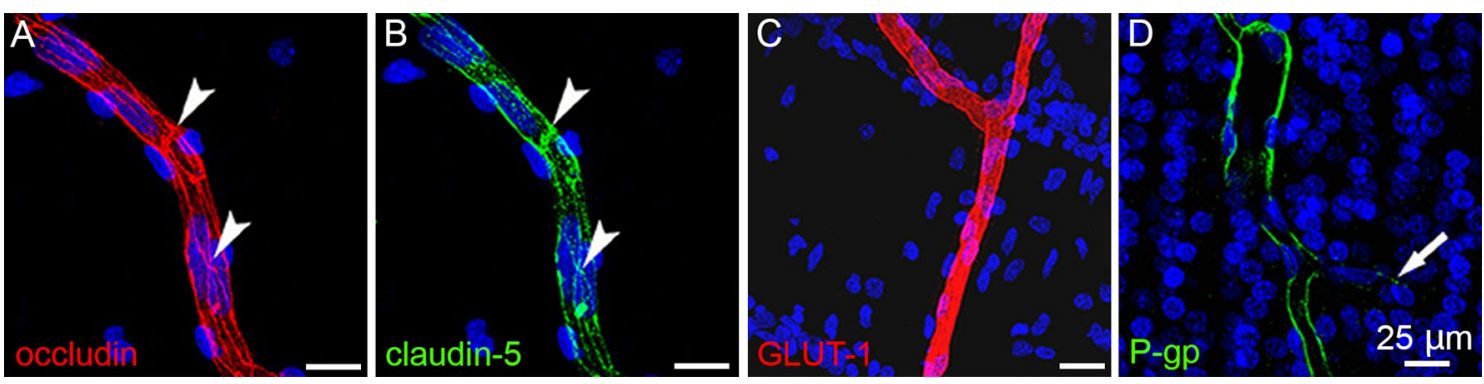

Fig. 2 Confocal images of key BBB markers stained in human cerebral cortex at mid-gestation tissue sections (from [126]). A, B Occludin and claudin-5 display clear junctional distributions with individual endothelial cells wrapping around to form junctions with themselves and neighboring cells. C, D GLUT-1 and P-gp, critical nutrient and efflux transporters, display uniform expression 
expression is critical to facilitate transport of glucose to meet the high metabolic demand of the brain. The P-glycoprotein (P-gp) efflux pump is one of several multi-spectrum efflux transporters present in brain endothelium and is predominantly localized to the luminal membrane. Expression of the P-gp pump verifies the potential for efflux, an important component of the BBB barrier function (see "Efflux transport" section for more details).

A minimum set of criteria for staining in vitro BBB models is: Continuous TJ proteins (i.e. claudin-5, occludin, and zona occludens-1) localized to cell-cell junctions, and uniform expression of nutrient and efflux transporters.

\section{Transendothelial electrical resistance (TEER)}

TEER measures the ionic resistance of cell monolayers. The equivalent circuit for endothelial and epithelial monolayers has two components, the resistance associated with paracellular ion transport and the resistance associated with ion transport across the apical and luminal cell membranes (Fig. 3) [57]. For the limiting case where paracellular resistance is large, implying negligible paracellular permeability, then TEER values are determined by the conductance of the cell membranes. TEER is difficult to measure in tissue-engineered microvessels since there is usually a low resistance pathway between the lumen and surrounding matrix at the entry and exit. One solution to this problem is to measure both TEER and the

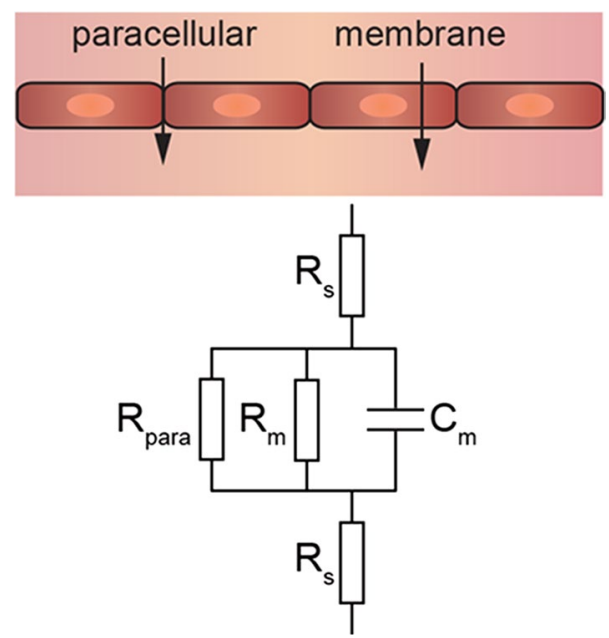

Fig. 3 Schematic illustration of the equivalent circuit for the impedance of a confluent monolayer. $R_{\text {para }}$-resistance associated with paracellular ion transport, $R_{m}$-resistance associated with ion transport across the cell membrane (i.e. through ion channels), $C_{m}$-capacitance associated with the cell membranes, $R_{s}$ - resistance associated with the media. If $R_{\text {para }}>R_{m}$ then paracellular ion transport is negligible and TEER values are determined by the resistance (1/ conductance) of the endothelial cell membranes permeability of a small molecule (e.g. Lucifer yellow) in a transwell assay, and the permeability of the small molecule in microvessels. If the small molecule permeability is the same in $2 \mathrm{D}$ and $3 \mathrm{D}$, and the TEER value in $2 \mathrm{D}$ is in the physiological range, then this implies that the tissue engineered model has physiological TEER. However, this method should be used with caution: although TEER is approximately inversely related to permeability, the relationship is non-linear and dependent on the endothelial cell type and solute $[5,127]$. For example, iPSC-derived hBMECs with TEER above $900 \Omega \mathrm{cm}^{2}$ display a constant IgG permeability, indicating this critical cutoff for physiological studies of large molecule transport [5].

Measurements in pial and arterial microvessels in rats and pial microvessels in frogs have shown TEER values in the range 1500-6000 $\Omega \mathrm{cm}^{2}$ [128-130]. Calculations based on the conductance and density of ion channels predict BMEC electrical resistance of $4000-8000 \Omega \mathrm{cm}^{2}$ [128, 131]. In contrast, TEER for primary and immortalized BMECs in monoculture are typically $\leq 200 \Omega$ $\mathrm{cm}^{2}$ [132-134]. The TEER of iPSC-derived BMECs are typically $\geq 1500 \Omega \mathrm{cm}^{-2}$, within the range obtained for microvessels in animal models $[1,2,4,5]$. An important implication of the observation that physiological TEER is achieved with iPSC-derived BMECs in 2D, is that cylindrical geometry, shear flow and co-culture are not essential for the tight junction formation.

\section{Permeability}

Tight junctions effectively block paracellular transport and hence small molecules cross the normal BBB either by passive diffusion or by carrier- or receptor-mediated transport. Downregulation of tight junctions can lead to disruption of the BBB and the onset of paracellular transport. Since many primary and immortalized cell lines do not exhibit physiological TEER, it is likely that the permeability values measured in Transwell ${ }^{\circledR}$ experiments utilizing these cells reflect contributions from both paracellular and transcellular transport pathways.

Defining quantitative benchmarks for barrier function is surprisingly difficult, and almost all quantitative in vivo data comes from animal models. The discovery of the BBB dates back to the observation by Paul Ehrlich that systemically injected Trypan blue stains all organs except the brain (Fig. 4A) [135, 136]. These experiments have subsequently been repeated with other dyes, such as Evans blue (961 Da) in many animal models (Fig. 4B, C) [135]. These dyes do not appreciably enter the brain as they are bound to albumin in circulation $(67 \mathrm{kDa}, \sim 10 \mathrm{~nm}$ in size). The in vivo permeability of the BBB to various solutes has been performed using various experimental protocols in animal models. The permeability of Lucifer yellow in $15 \mu \mathrm{m}$ pial post-capillary venules in a rat model 

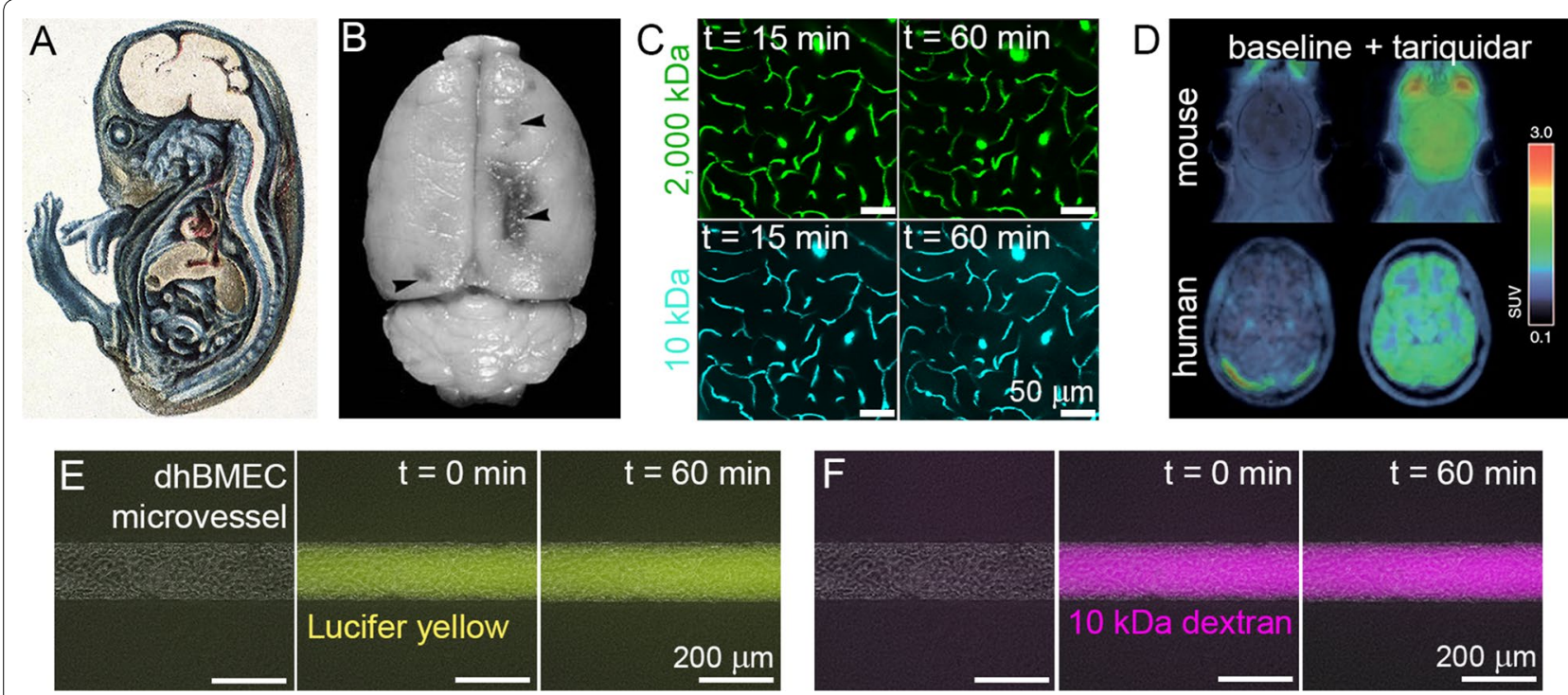

Fig. 4 Blood-brain barrier permeability. A Guinea pig embryo injected with trypan blue demonstrates restriction of dye entry into CNS (from [135]). B Brain of a rat with chronic hypertension showing areas of Evans blue extravasation in the boundary zone areas (from [141]). C Adult mice injected with fluorescently-labeled dextrans (10 and $2000 \mathrm{kDa}$ ) and imaged with two-photon microscopy show lack of significant dye extravasation over $1 \mathrm{~h}$ (from [142]). D Positron emission tomography (PET) imaging of radiolabeled verapamil in mouse and human brains with and without p-glycoprotein inhibition using tariquidar. The color bar indicates brain-to-plasma ratio, a measure of drug penetration (from [143]). E, F Permeability experiments using Lucifer yellow and $10 \mathrm{kDa}$ dextran in tissue-engineered iPSC-derived brain microvessels (from [24])

was reported to be $1-2 \times 10^{-7} \mathrm{~cm} \mathrm{~s}^{-1}$ [137]. In zebrafish, where the cerebrovasculature is visible without surgical manipulation, $10 \mathrm{kDa}$ dextran was not observed to enter the brain parenchyma [138]. However, in a series of experiments using multiphoton microscopy in $20-40 \mu \mathrm{m}$ pial post-capillary venules in a rat model $[139,140]$, the permeability of sodium fluorescein $(332 \mathrm{Da})$ was determined to be $1.46 \times 10^{-6} \mathrm{~cm} \mathrm{~s}^{-1}$ and the permeability of $10 \mathrm{kDa}$ dextran was $3.1 \pm 1.3 \times 10^{-7} \mathrm{~cm} \mathrm{~s}^{-1}$. While the permeability of the larger $10 \mathrm{kDa}$ dextran is fivefold smaller than fluorescein, it is close to the permeability of the small molecule Lucifer yellow as described above [137]. Thus, there are discrepancies across in vivo studies in animal models that make it difficult to provide definitive values for benchmarking. Therefore, we provisionally suggest that for tissue-engineered models: (1) the permeability of Lucifer yellow should be $\leq 2 \times 10^{-7} \mathrm{~cm} \mathrm{~s}^{-1}$, and (2) the permeability of $10 \mathrm{kDa}$ dextran, solutes that bind to albumin, or other large molecules (e.g. albumin) should be negligible $\left(\leq 1 \times 10^{-7} \mathrm{~cm} \mathrm{~s}^{-1}\right)$.

In vitro models of the $\mathrm{BBB}$ generally fail to achieve physiological permeability. In one of the very few studies of tissue-engineered BBB microvessels incorporating primary human BMECs, astrocytes, and pericytes, the permeability of $3 \mathrm{kDa}$ dextran was reported to be $2-4 \times 10^{-6} \mathrm{~cm} \mathrm{~s}^{-1}$ [43]. As acknowledged by the authors, this high permeability for a large molecule does not recapitulate BBB barrier function and is likely associated with low TEER values $\left(40-50 \Omega \mathrm{cm}^{2}\right)$ of the primary BMECs. In iPSC-derived human BMEC microvessels (with no other cell types), the permeability of Lucifer yellow was reported to be $2-3 \times 10^{-7} \mathrm{~cm} \mathrm{~s}^{-1}$ (Fig. 4E) [24], close to values reported in a rat model [137]. In addition, the permeability of $10 \mathrm{kDa}$ fluorescently labeled dextran was below the detection limit (Fig. 4F) [24]. TEER values for the iPSC-derived hBMECs were $>1500 \Omega \mathrm{cm}^{2}$, in the range thought to be physiological. Taken together these results further support the hypothesis that physiological TEER values are associated with negligible paracellular transport and permeabilities that are related to transcellular transport alone. A recent report of a self-organized human BBB microvascular network reported $10 \mathrm{kDa}$ dextran permeability of $\sim 2 \times 10^{-7} \mathrm{~cm} \mathrm{~s}^{-1}$, matching values reported from multiphoton studies [45].

\section{Efflux transport}

To regulate entry of small molecules into the brain by passive transport, BMECs express an array of efflux transporters, the most well-known of which are the P-glycoprotein (P-gp) and Breast Cancer Resistant Protein (BCRP) pumps [144]. These pumps are generally polarized on the luminal surface of BMECs and are capable of effluxing a wide range of chemically diverse compounds [145].

A common functional method to confirm the presence of efflux pumps is to perform permeability experiments 
in a Transwell ${ }^{\circledR}$ assay, measuring both apical-to-basolateral (AB) and basolateral-to-apical (BA) permeability of a solute that is a substrate for the pump. If the efflux pump is polarized to the apical surface on the BMECs then the efflux ratio (ER) which is defined as $\mathrm{P}_{\mathrm{BA}} / \mathrm{P}_{\mathrm{AB}}$, is $>1$. Due to the variations in experimental measurements, a molecule is generally considered to be an efflux substrate if ER $>2$. Efflux ratios are typically in the range of $2-10$, although higher values have been reported [146]. Confirmation that the ER is related to differences in efflux transport can be obtained by introducing an inhibitor. For complete inhibition of a solute that is only a substrate of the target efflux pump, the ER will decrease to 1.0. However, the inhibitor may not be completely effective in blocking efflux and/or efflux at other pumps may result in only a small decrease in ER.

In tissue-engineered models it is difficult to perform bidirectional permeability measurements and hence experiments generally rely on measurement of differences in permeability (lumen to matrix) with and without inhibitor. This method is most effective if the inhibitor is very efficient in blocking the target efflux pump (e.g. P-gp) and the solute is only a substrate for that efflux pump. A common approach is to measure the permeability of Rhodamine 123 which is a P-gp substrate and to use a P-gp inhibitor such as cyclosporin $\mathrm{A}$ or tariquidar to reduce efflux. An alternative approach is to use gene editing to delete or knock down an efflux pump to replicate results from genetically engineered mouse models, however, this method may result in secondary effects that also modulate barrier function. The presence of efflux pumps can be confirmed by immunohistochemistry, although it is difficult to quantify absolute expression levels or polarization to the luminal or abluminal membrane.

Studies of efflux in humans are rare. Continuous intravenous infusion of tariquidar, a P-gp inhibitor, increased the brain penetration of radio-labeled verapamil by 2.7 -fold in healthy human subjects, a $60 \%$ reduction in P-gp activity (Fig. 4D) [147]. Verapamil is used to treat migraines, but is also used as a substrate and inhibitor of the P-gp pump. Dual knockout of P-gp and BCRP in a mouse model resulted in a 40-fold increase in CNS penetration of efflux substrates [148].

\section{Endothelial cell turnover}

Under quiescent conditions, the net turnover rate of BMECs is expected to approach zero. The net turnover rate is the difference between the proliferation rate and the rate of cell loss. Results from thymidine labeling in mice suggest that the turnover rate of endothelial cells in the brain is about $0.04 \% \mathrm{~h}^{-1}$ [149], an order of magnitude or more lower than endothelial cells in other tissues [150, 151]. Two-photon microscopy studies in capillary beds in the motor and somatosensory cortex of mice show no change in either capillary segment diameter, capillary segment length, and the position of branch points over about 30 days [152, 153]. Assuming that these results imply no proliferation/loss over the imaging period, we estimate an upper limit of the net turnover rate of $0.001 \%$ $\mathrm{h}^{-1}$. In one of these studies, BrdU labeling of cortical microvessels in mice revealed no detectable endothelial cell division over 10 days during the post-natal period, indicating a cell division rate of zero during that time frame [153]. Additionally, formation and elimination of microvessel branch points decreased with age, resulting in no formation or elimination of microvessel branch points over 30 days in adult mice [153]. Turnover is an important but often overlooked parameter in benchmarking tissue engineered vascular models. Validation is complicated by the lack of physiological data for the dynamics of endothelial cell division and loss in vivo in humans or animal models. Based on intravital microscopy experiments we provisionally suggest that target values for cell division and cell death are $\leq 0.001 \% \mathrm{~h}^{-1}$, with a net turnover rate approaching zero.

\section{Astrocytes}

Astrocytes are involved in many processes in the brain, including neurotransmitter uptake and release, stress response, and neurovascular coupling [154-157]. Astrocytes typically have star-shaped morphologies with small cell bodies and radial branched processes that occupy distinct domains (Fig. 5A) [158]. These processes terminate in end-feet that completely ensheath capillaries (Fig. 5B) [157-159]. Human cortical astrocytes have a cell body approximately $10 \mu \mathrm{m}$ in diameter, and extend $\sim 40$ primary process from the cell body resulting in an overall domain of about $150 \mu \mathrm{m}$ [158]. In contrast, mouse astrocytes occupy domains of about $50 \mu \mathrm{m}$ and extend fewer radial processes than their human counterparts [158].

In response to trauma or pathological tissue damage, astrocytes become activated, a process known as reactive gliosis [160-162]. Astrocyte activation is characterized by marked changes in protein expression [160, 162-164], a hallmark of which is the increased expression of intermediate filament proteins including glial fibrillary acidic protein (GFAP) and vimentin $[160,165]$. Astrocytes also secrete a wide range of soluble growth factors (such as bFGF and GDNF), inflammatory cytokines, and extracellular matrix proteins $[160,163]$.

GFAP expression is often used as an astrocyte-specific marker, even though it is primarily a marker of activated astrocytes. S100B is also widely used to identify astrocytes, although expression may be limited to certain astrocyte subsets [166]. Two markers associated with BMEC-astrocyte signaling are aquaporin 4 (AQP4) 


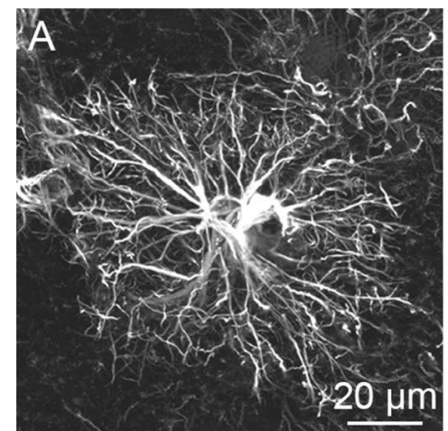

protoplasmic astrocyte in the human brain

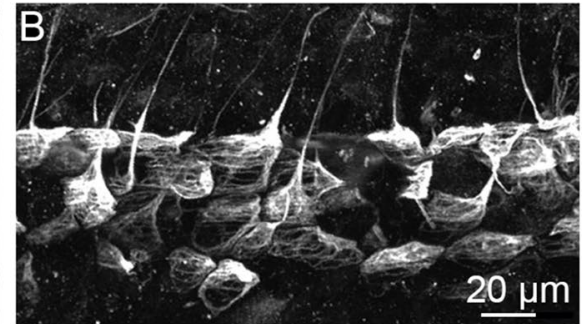

astrocyte endfeet surrounding a microvessel in the human brain

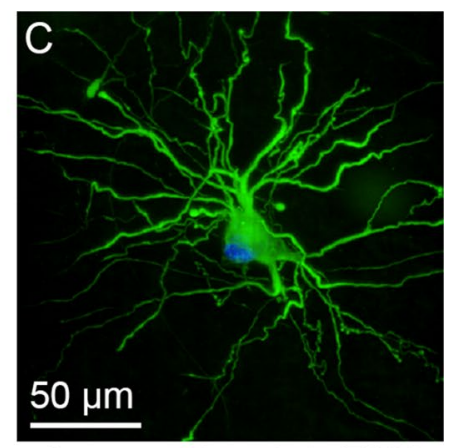

human astrocyte in ECM

Fig. 5 Astrocyte morphology. A Protoplasmic astrocyte in the human brain (adapted from [158]). B Astrocyte end-feet surrounding a microvessel in the human brain (adapted from [158]). C Astrocyte derived from neural progenitor cell cultured in an extracellular matrix consisting of collagen type I, Matrigel, and hyaluronic acid (from [170])

and the potassium ion channel, KiR4.1, which are highly expressed in astrocyte end-feet surrounding brain capillaries [167, 168].

In BBB research, astrocytes are usually cultured in 2D (e.g. in the basolateral chamber in a Transwell ${ }^{\circledR}$ assay). Physiological morphology is not believed to be critical to these experiments since the purpose is simply to provide a source of soluble factors secreted by the astrocytes. In $2 \mathrm{D}$ culture, the morphology and number of processes emanated depends on the surface coating, and the cells generally express GFAP, characteristic of activation [169]. In $3 \mathrm{D}$ culture, the morphology and level of GFAP expression in human astrocytes is strongly dependent on the composition and mechanical properties of the matrix material [170]. Human astrocytes cultured in gels composed of collagen, HA, and Matrigel exhibited a highly branched morphology, typical of their morphology in vivo (Fig. 5 C), and very low levels of GFAP expression, a hallmark of quiescent cells [170].

Suggested benchmarks for incorporation of astrocytes into BBB models: (1) small cell body with radial branched processes with a domain size of about $150 \mu \mathrm{m}$. (2) Endfeet extending to capillaries or microvessels. (3) High expression of astrocyte markers KiR4.1 and AQP4. (4) Negligible expression of activation markers such as GFAP and vimentin under quiescent conditions.

\section{Pericytes}

Defining the morphology, organization, and function of pericytes in the brain has been inconsistent and controversial. Recent imaging studies in genetically engineered mouse models suggest that much of the confusion over pericyte function arises from the diversity of perivascular cell types in the cerebrovasculature [152, 171-174]. Perivascular cells surrounding arterioles express smooth muscle actin ( $\alpha$ SMA) and are identified as vascular smooth muscle cells (VSMCs) [172, 173]. These cells extend processes around the circumference of the arterioles that appear as neighboring rings or bands up to $7 \mu \mathrm{m}$ wide around microvessels (Fig. 6A, C).

In capillaries, perivascular cells are sparse and express platelet derived growth factor receptor (PDGFR $\beta$ ), the proteoglycan neural/glial antigen 2 (NG2), and CD13 $[171-173,175,176]$. These cells are defined as pericytes, and are characterized by a bump-on-a-log morphology with an ovoid-shaped nucleus and narrow processes that are predominantly aligned along the capillary, and are completely surrounded by basement membrane (Figs. 1D, 6B, D, E) [152, 172-174]. The average density of pericytes in mouse models is about one cell per $80 \mu \mathrm{m}$ length of capillary [152]. The ratio of pericytes to endothelial cells has been reported at approximately 1:5 by electron microscopy analysis of a small sample of rat cerebral capillaries [177]. In post-capillary venules, the perivascular cells, also identified as pericytes, extend both longitudinal and circumferential processes (Fig. 6C).

The VSMCs that surround arterioles are contractile and are believed to contribute to neurovascular coupling [172, 173], however, the role of capillary pericytes in blood flow regulation remains to be established [178, 179]. A further complication is that perivascular cells in the transition region from arterioles to capillaries express intermediate levels of $\alpha$ SMA and are difficult to classify as either VSMCs or pericytes.

In cell culture, pericytes are multipotent, with the capability to be differentiated into mesenchymal cells and neural cells [180-183]. This discovery led to the hypothesis that pericytes may be a source of other brain-specific cell types and play a role in stress and injury response in the brain [180]. However, this remains to be confirmed 


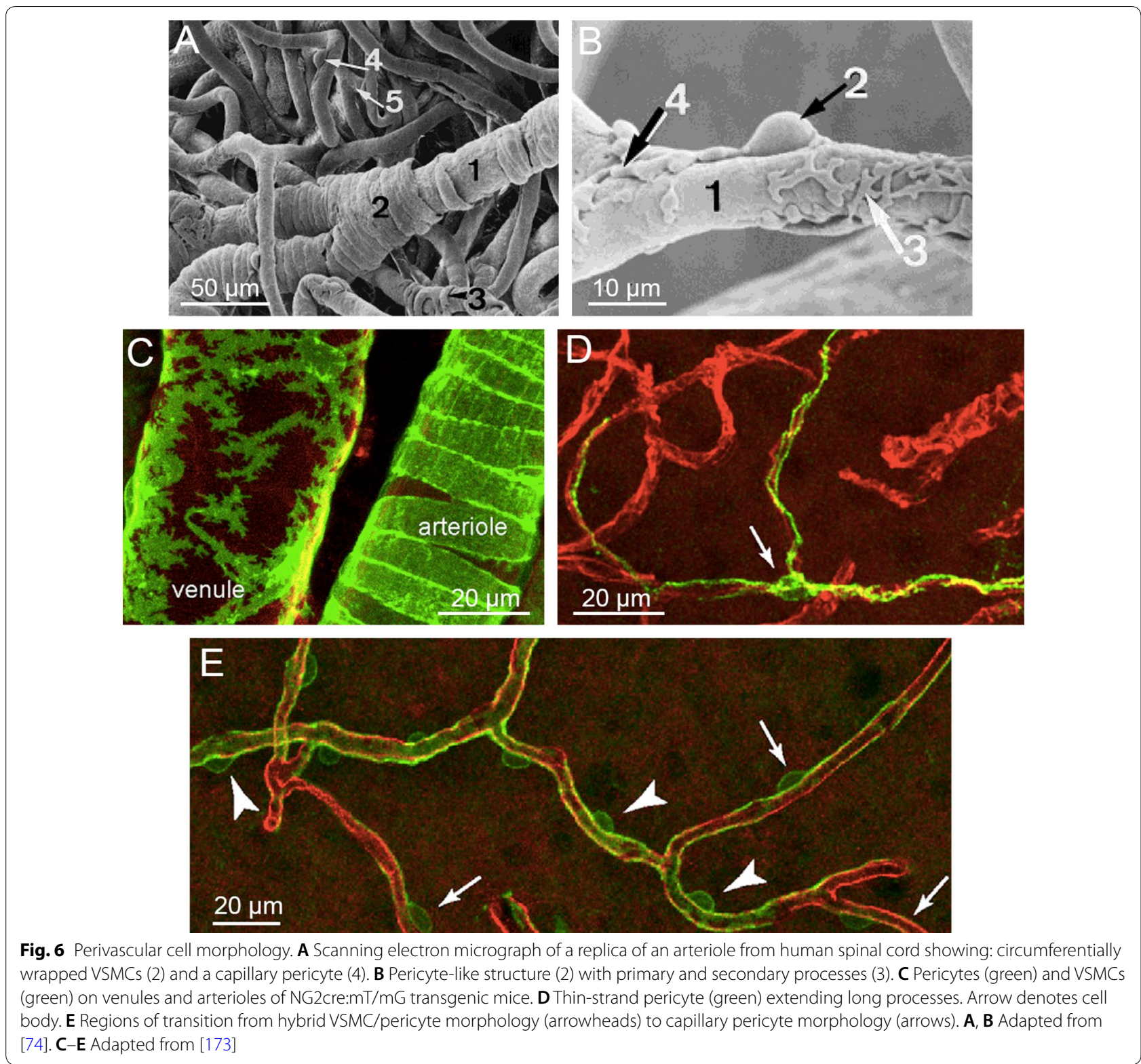

since recent evidence suggests that pericytes maintain their identity during normal aging or in pathological settings [184], and hence they are multipotent only after in vitro culture, and not in vivo.

Perivascular cells play a major role in angiogenesis where activated endothelial cells recruit pericytes through secretion of PDGF-BB which binds to PDGFR $\beta$ with high affinity. PDGF-BB is localized to the endothelium through binding to heparin sulfate proteoglycans (HSPGs). The role of pericytes in angiogenesis is largely derived from studies of neovascularization associated with diseases such as cancer [185], and hence the response of pericytes to disease- or trauma-induced angiogenesis remains to be elucidated. In a microfluidic model of angiogenesis involving microvessels formed from human umbilical vein endothelial cells, co-culture resulted in recruitment of human placental pericytes to sprouts and refinement of the nascent vasculature [186].

Suggested benchmarks for incorporation of pericytes into BBB models: (1) pericytes are located on the abluminal surface of models of capillaries or post-capillary venules. (2) Pericytes exhibit bump-on-a-log morphology with predominantly longitudinally aligned processes. (3) Pericytes express PDGFR $\beta$, NG2, and CD13; do not express $\alpha$ SMA. (4) Pericytes are embedded within basement membrane. 


\section{Astrocytes, pericytes, and barrier function}

Numerous in vitro studies have reported that TEER of endothelial monolayers is increased in the presence of astrocytes, astrocyte extract, or pericytes, and this trend is cited as evidence of the role of astrocytes and pericytes in upregulation and maintenance of barrier function in vivo [187-195]. However, in many of these experiments, the final TEER values are still well below physiological (1500-8000 $\Omega \mathrm{cm}^{2}$ ), casting some doubt on the in vivo relevance of these increases (Fig. 7). For example, the TEER of primary murine BMECs increased from about $35 \Omega \mathrm{cm}^{2}$ to about $140 \Omega \mathrm{cm}^{2}$ with pericytes in the basolateral chamber [187]. As described previously, monolayers of iPSC-derived hBMECs exhibit TEER values in the physiological range, particularly when derived with retinoic acid [2, 4], suggesting that astrocytes and pericytes are not essential for achieving physiological TEER values in in vitro models, provided they are cultured in the presence of key exogenous factors. However, monolayers of iPSC-derived hBMECs cultured under conditions with sub-physiological TEER values have approached $[15,21]$ or attained $[2,17]$ physiological values when co-cultured with astrocytes and/or pericytes (Fig. 7). Taken together, these results suggest that astrocytes and pericytes are not responsible for establishing barrier function, but can secrete factors that promote

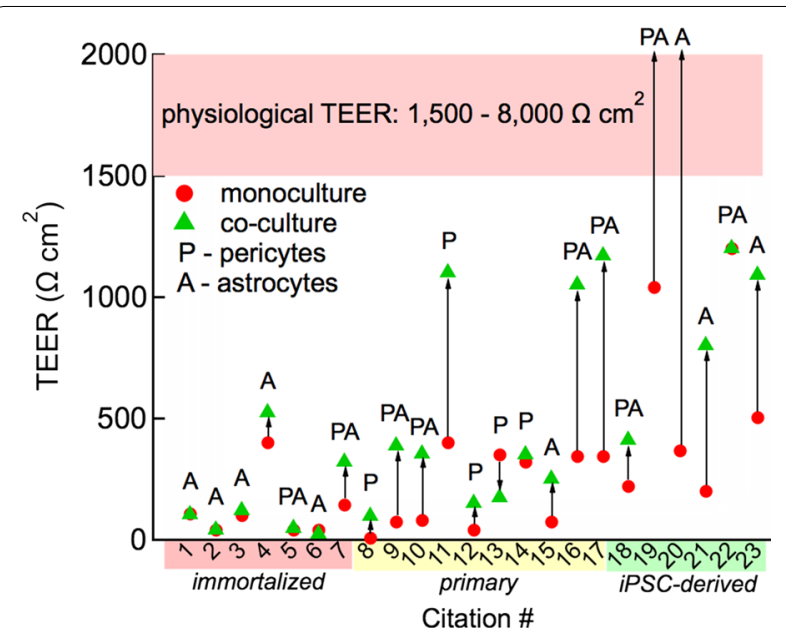

Fig. 7 Compilation of changes of TEER values for BMEC monolayers with or without astrocytes or astrocyte-conditioned media (A), or pericytes $(P)$ in the basolateral chamber or on the basolateral side of the Transwell ${ }^{\circledR}$ membrane. Note that a wide range of primary, immortalized, and neural progenitor cell-derived cells from multiple species have been classified as either astrocytes or pericytes for simplicity, but individual references should be examined for cell sourcing details. Key for citations: 1-[196], 2-[197], 3-[194], 4[191], 5-[195], 6-[132], 7-[17], 8-[188], 9-[190], 10—[189], 11[193], 12-[187], 13-[198], 14-[199], 15-[200], 16 and 17 [201], 18-[1], 19-[2], 20—[17], 21-[15], 22-[9], 23-[21] recovery or repair. If this hypothesis is correct, then we would expect that co-culture of astrocytes and/or pericytes with optimally differentiated hBMECs would have no effect on barrier tightness, but may aid in recovery of barrier function in response to simulation of injury or stress. Whether these results from in vitro models recapitulate the roles of these cells in the neurovascular unit remains to be established.

\section{Summary}

Here we describe 12 parameters for benchmarking in vitro BBB models. These parameters are associated with structure (ultrastructure, wall shear stress, geometry), microenvironment (basement membrane and extracellular matrix), barrier function (TEER, permeability, efflux transport), cell function (expression of BBB markers, turnover), and co-culture with other cell types (astrocytes and pericytes). The relevant benchmarks are dependent on the purpose of the model and provide a starting point to guide validation and future developments.

Although the complexity of tissue-engineered $\mathrm{BBB}$ models has advanced significantly in recent years, incorporation of multiple characteristics of the $\mathrm{BBB}$ remains challenging. Nonetheless, recent advances in tissue engineering and stem cell technology provide the foundation for new frontiers in BBB modeling. (1) Improved visualization of barrier function and turnover: quantifying barrier function and turnover in vivo is difficult and hence new models that enable imaging of these functions in real-time would increase understanding of BMECs in health and disease [202]. (2) Hierarchical BBB models comprised of an arteriole, capillary bed, and venule. Templating approaches generally mimic the structure of post-capillary venules, while self-organization approaches mimic brain capillaries. Recent advances in transcriptomics have precisely mapped zonation of the brain vasculature [203], providing a basis for comparison. Additionally, novel techniques to generate capillaries based on sprouting angiogenesis or growth along patterned channels may support this aim [35, 204]. (3) Recapitulating neurovascular coupling: neuronal activity and blood supply are matched via changes in arteriole and capillary tone mediated by signaling between endothelial cells, pericytes, astrocytes and neurons. Incorporation of neurons into BBB-on-a-chip models that are responsive to neuronal activity would represent a significant advance. Recently, neurometabolic coupling was demonstrate in vitro [205]. (4) Recapitulating human disease: complex microfluidic models of brain disease typically lack endothelial cells; for example, recent work demonstrated microfluidic triculture of neurons, astrocytes 
and microglia to mimic Alzheimer's disease [206]. Integration of microfluidic models of brain disease and of the BBB models will support studies of human disease with increasing fidelity.

\section{Authors' contributions}

JGD, JJJ, RML and PCS wrote the manuscript. All authors read and approved the final manuscript.

\section{Author details}

${ }^{1}$ Institute for Nanobiotechnology, Johns Hopkins University, Baltimore, MD, USA. ${ }^{2}$ Department of Materials Science and Engineering, Johns Hopkins University, Baltimore, MD, USA. ${ }^{3}$ Department of Chemical and Biomolecular Engineering, Johns Hopkins University, Baltimore, MD, USA. ${ }^{4}$ Department of Biomedical Engineering, Johns Hopkins University School of Medicine, Baltimore, MD, USA. ${ }^{5} 120$ Croft Hall, Johns Hopkins University, 3400 North Charles Street, Baltimore, MD 21218, USA.

\section{Acknowledgements}

JGD acknowledges support from the Nanotechnology for Cancer Research training program. JJJ acknowledges support from the ARCS Foundation. RML acknowledges a National Science Foundation Graduate Research Fellowship under Grant No. DGE1746891.

\section{Competing interests}

The authors declare that they have no competing interests.

\section{Availability of data and materials}

Not applicable.

\section{Consent for publication}

Not applicable.

\section{Ethics approval and consent to participate}

Not applicable.

\section{Funding}

The authors gratefully acknowledge support from DTRA (HDTRA1-15-1-0046).

\section{Publisher's Note}

Springer Nature remains neutral with regard to jurisdictional claims in published maps and institutional affiliations.

Received: 27 August 2018 Accepted: 11 November 2018

Published online: 04 December 2018

\section{References}

1. Lippmann ES, et al. Derivation of blood-brain barrier endothelial cells from human pluripotent stem cells. Nat Biotechnol. 2012;30(8):783-91.

2. Lippmann ES, et al. A retinoic acid-enhanced, multicellular human blood-brain barrier model derived from stem cell sources. Sci Rep. 2014:4:4160.

3. Wilson HK, et al. Exploring the effects of cell seeding density on the differentiation of human pluripotent stem cells to brain microvascular endothelial cells. Fluids Barriers CNS. 2015;12:13.

4. Katt ME, et al. Human brain microvascular endothelial cells derived from the BC1 iPS cell line exhibit a blood-brain barrier phenotype. PLoS ONE 2016:11(4):e0152105.

5. Mantle JL, Min L, Lee KH. Minimum transendothelial electrical resistance thresholds for the study of small and large molecule drug transport in a human in vitro blood-brain barrier model. Mol Pharm. 2016;13(12):4191-8

6. Patel R, Alahmad AJ. Growth-factor reduced Matrigel source influences stem cell derived brain microvascular endothelial cell barrier properties. Fluids Barriers CNS. 2016;13:6.
7. Page S, Munsell A, Al-Ahmad AJ. Cerebral hypoxia/ischemia selectively disrupts tight junctions complexes in stem cell-derived human brain microvascular endothelial cells. Fluids Barriers CNS. 2016;13:16.

8. Gallagher $\mathrm{E}_{\text {, et }}$ al. In vitro characterization of pralidoxime transport and acetylcholinesterase reactivation across MDCK cells and stem cellderived human brain microvascular endothelial cells (BC1-hBMECs). Fluids Barriers CNS. 2016;13(1):10.

9. Appelt-Menzel A, et al. Establishment of a human blood-brain barrier co-culture model mimicking the neurovascular unit using induced pluri- and multipotent stem cells. Stem Cell Rep. 2017;8(4):894-906.

10. Hollmann EK, et al. Accelerated differentiation of human induced pluripotent stem cells to blood-brain barrier endothelial cells. Fluids Barriers CNS. 2017;14:9.

11. Al-Ahmad AJ. Comparative study of expression and activity of glucose transporters between stem cell-derived brain microvascular endothelial cells and hCMEC/D3 cells. Am J Physiol Cell Physiol. 2017;313(4):C421-9.

12. Kim BJ, et al. Modeling group B Streptococcus and blood-brain barrier interaction by using induced pluripotent stem cell-derived brain endothelial cells. Msphere. 2017;2(6):e00398-17.

13. Kokubu Y, Yamaguchi T, Kawabata K. In vitro model of cerebral ischemia by using brain microvascular endothelial cells derived from human induced pluripotent stem cells. Biochem Biophys Res Commun. 2017;486:577-83.

14. Lim RG, et al. Huntington's disease iPSC-derived brain microvascular endothelial cells reveal WNT-mediated angiogenic and blood-brain barrier deficits. Cell Rep. 2017;19(7):1365-77.

15. Canfield SG, et al. An isogenic blood-brain barrier model comprising brain endothelial cells, astrocytes, and neurons derived from human induced pluripotent stem cells. J Neurochem. 2017;140(6):874-88.

16. Vatine GD, et al. Modeling psychomotor retardation using iPSCs from MCT8-deficient patients indicates a prominent role for the blood-brain barrier. Cell Stem Cell. 2017;20(6):p. 831-+.

17. Wang Yl, Abaci HE, Shuler ML. Microfluidic blood-brain barrier model provides in vivo-like barrier properties for drug permeability screening. Biotechnol Bioeng. 2017:114(1):184-94.

18. Patel R, Page S, Al-Ahmad AJ. Isogenic blood-brain barrier models based on patient-derived stem cells display inter-individual differences in cell maturation and functionality. J Neurochem. 2017;142(1):74-88.

19. Qian TC, et al. Directed differentiation of human pluripotent stem cells to blood-brain barrier endothelial cells. Sci Adv. 2017;3(11):e1701679.

20. Hollmann EK, et al. Accelerated differentiation of human induced pluripotent stem cells to blood-brain barrier endothelial cells. Fluids Barriers CNS. 2017;14(1):9.

21. Ribecco-Lutkiewicz $M$, et al. A novel human induced pluripotent stem cell blood-brain barrier model: applicability to study antibody-triggered receptor-mediated transcytosis. Sci Rep. 2018;8:1873.

22. Stebbins MJ, et al. Activation of RAR, RAR, or RXR increases barrier tightness in human induced pluripotent stem cell-derived brain endothelial cells. Biotechnol J. 2018;13(2):1700093.

23. Katt ME, et al. Functional brain-specific microvessels from iPSC-derived human brain microvascular endothelial cells: the role of matrix composition on monolayer formation. Fluids Barriers CNS. 2018;15:7.

24. Linville RL, et al. Human iPSC-derived blood-brain barrier microvessels: validation of barrier function and endothelial cell behavior. Biomaterials. 2019;190-191:24-37.

25. Al-Ahmad AJ, et al. Hyaluronan impairs the barrier integrity of brain microvascular endothelial cells through a CD44-dependent pathway. J Cereb Blood Flow Metab. 2018:271678X18767748.

26. Chiou B, et al. Endothelial cells are critical regulators of iron transport in a model of the human blood-brain barrier. J Cereb Blood Flow Metab. 2018:271678X18783372.

27. Alimonti JB, et al. Zika virus crosses an in vitro human blood brain barrier model. Fluids Barriers CNS. 2018:15:15.

28. Yu J, et al. Human induced pluripotent stem cells free of vector and transgene sequences. Science. 2009;324(5928):797-801.

29. Chou BK, et al. Efficient human iPS cell derivation by a non-integrating plasmid from blood cells with unique epigenetic and gene expression signatures. Cell Res. 2011;21(3):518-29.

30. Neuwelt EA, et al. Engaging neuroscience to advance translational research in brain barrier biology. Nat Rev Neurosci. 2011;12(3):169-82. 
31. Neuwelt $E$, et al. Strategies to advance translational research into brain barriers. Lancet Neurol. 2008;7(1):84-96.

32. Helms HC, et al. In vitro models of the blood-brain barrier: an overview of commonly used brain endothelial cell culture models and guidelines for their use. J Cereb Blood Flow Metab. 2016;36(5):862-90.

33. Gastfriend BD, Palecek SP, Shusta EV. Modeling the blood-brain barrier: beyond the endothelial cells. Curr Opin Biomed Eng. 2018;5:6-12.

34. Bogorad MI, et al. Review: in vitro microvessel models. Lab Chip. 2015;15(22):4242-55.

35. Bogorad MI, et al. Tissue-engineered 3D microvessel and capillary network models for the study of vascular phenomena. Microcirculation. 2017;24:e12360.

36. Brown JA, et al. Recreating blood-brain barrier physiology and structure on chip: a novel neurovascular microfluidic bioreactor. Biomicrofluidics. 2015;9(5):054124.

37. Booth $\mathrm{R}, \mathrm{Kim} \mathrm{H}$. Characterization of a microfluidic in vitro model of the blood-brain barrier (mu BBB). Lab Chip. 2012;12(10):1784-92.

38. Yeon $\mathrm{JH}$, et al. Reliable permeability assay system in a microfluidic device mimicking cerebral vasculatures. Biomed Microdevice. 2012;14(6):1141-8.

39. Prabhakarpandian B, et al. SyM-BBB: a microfluidic blood brain barrier model. Lab Chip. 2013;13(6):1093-101.

40. Adriani $G$, et al. A 3D neurovascular microfluidic model consisting of neurons, astrocytes and cerebral endothelial cells as a blood-brain barrier. Lab Chip. 2017;17(3):448-59.

41. Wevers NR, et al. A perfused human blood-brain barrier on-a-chip for high-throughput assessment of barrier function and antibody transport. Fluids Barriers CNS. 2018;15(1):23

42. $\mathrm{Cho} \mathrm{H}$, et al. Three-dimensional blood-brain barrier model for in vitro studies of neurovascular pathology. Sci Rep. 2015;5:15222.

43. Herland A, et al. Distinct contributions of astrocytes and pericytes to neuroinflammation identified in a 3D human blood-brain barrier on a chip. PLoS ONE. 2016;11(3):e0150360.

44. Partyka PP, et al. Mechanical stress regulates transport in a compliant 3D model of the blood-brain barrier. Biomaterials. 2017;115:30-9.

45. Campisi M, et al. 3D self-organized microvascular model of the human blood-brain barrier with endothelial cells, pericytes and astrocytes. Biomaterials. 2018;180:117-29.

46. Bang $\mathrm{S}$, et al. A low permeability microfluidic blood-brain barrier platform with direct contact between perfusable vascular network and astrocytes. Sci Rep. 2017;7:8083.

47. Syvanen $\mathrm{S}$, et al. Species differences in blood-brain barrier transport of three positron emission tomography radioligands with emphasis on P-glycoprotein transport. Drug Metab Dispos. 2009;37(3):635-43.

48. Watase $\mathrm{K}$, Zoghbi HY. Modelling brain diseases in mice: the challenges of design and analysis. Nat Rev Genet. 2003;4(4):296-307.

49. Zlokovic BV. Neurovascular mechanisms of Alzheimer's neurodegeneration. Trends Neurosci. 2005;28(4):202-8.

50. Karbowski J. Scaling of brain metabolism and blood flow in relation to capillary and neural scaling. PLoS ONE. 2011;6(10):e26709.

51. Duvernoy H, Delon S, Vannson JL. The vascularization of the human cerebellar cortex. Brain Res Bull. 1983;11(4):419-80.

52. Schlageter KE, et al. Microvessel organization and structure in experimental brain tumors: microvessel populations with distinctive structural and functional properties. Microvasc Res. 1999;58(3):312-28.

53. Risser $L$, et al. A $3 D$-investigation shows that angiogenesis in primate cerebral cortex mainly occurs at capillary level. Int J Dev Neurosci. 2009:27(2):185-96.

54. Risser $\mathrm{L}$, et al. From homogeneous to fractal normal and tumorous microvascular networks in the brain. J Cereb Blood Flow Metab. 2007;27(2):293-303

55. Heinzer $\mathrm{S}$, et al. Novel three-dimensional analysis tool for vascular trees indicates complete micro-networks, not single capillaries, as the angiogenic endpoint in mice overexpressing human VEGF(165) in the brain. Neuroimage. 2008;39(4):1549-58.

56. Meyer EP, et al. Altered morphology and $3 D$ architecture of brain vasculature in a mouse model for Alzheimer's disease. Proc Natl Acad Sci USA. 2008;105(9):3587-92.

57. Wong $A D$, et al. The blood-brain barrier: an engineering perspective. Front Neuroeng. 2013;6:7.
58. Abbott $\mathrm{NJ}$, et al. Structure and function of the blood-brain barrier. Neurobiol Dis. 2010;37(1):13-25.

59. Garcia JH, et al. Influx of leukocytes and platelets in an evolving brain infarct (Wistar rat). Am J Pathol. 1994;144(1):188-99.

60. Nacer A, et al. Neuroimmunological blood brain barrier opening in experimental cerebral malaria. PLoS Pathogens. 2012;8(10):e1002982.

61. Kienast $Y$, et al. Real-time imaging reveals the single steps of brain metastasis formation. Nat Med. 2010;16(1):116-22.

62. Larochelle C, Alvarez JI, Prat A. How do immune cells overcome the blood-brain barrier in multiple sclerosis? FEBS Lett. 2011;585(23):3770-80.

63. Holman DW, Klein RS, Ransohoff RM. The blood-brain barrier, chemokines and multiple sclerosis. Biochim Biophys Acta. 2011:1812(2):220-30.

64. Takeshita Y, Ransohoff RM. Inflammatory cell trafficking across the blood-brain barrier: chemokine regulation and in vitro models. Immunol Rev. 2012;248:228-39.

65. Owens T, Bechmann I, Engelhardt B. Perivascular spaces and the two steps to neuroinflammation. J Neuropathol Exp Neurol. 2008;67(12):1113-21.

66. Kristensson $\mathrm{K}$, et al. African trypanosome infections of the nervous system: parasite entry and effects on sleep and synaptic functions. Prog Neurobiol. 2010;91(2):152-71.

67. Reese TS, Karnovsky MJ. Fine structural localization of a blood-brain barrier to exogenous peroxidase. J Cell Biol. 1967;34(1):207-17.

68. Brightman MW, Reese TS. Junctions between intimately apposed cell membranes in the vertebrate brain. J Cell Biol. 1969:40(3):648-77.

69. Brightman MW. Morphology of blood-brain interfaces. Exp Eye Res. 1977:25:1-25.

70. Farkas E, Luiten PGM. Cerebral microvascular pathology in aging and Alzheimer's disease. Prog Neurobiol. 2001;64(6):575-611.

71. Nag S. Studies of cerebral vessels by transmission electron microscopy and morphometry. In: Nag S, editor. The blood-brain barrier: biological and research protocols. New York City: Humana Press; 2003. p. 37-50

72. Farquhar MG, Palade GE. Junctional complexes in various epithelia. J Cell Biol. 1963;17(2):375-412.

73. Tsukita S, Furuse M, Itoh M. Multifunctional strands in tight junctions. Nat Rev Mol Cell Biol. 2001;2(4):285-93.

74. Rodriguez-Baeza A, et al. Perivascular structures in corrosion casts of the human central nervous system: a confocal laser and scanning electron microscope study. Anat Rec. 1998;252(2):176-84.

75. Wolburg H, Liebner S, Lippoldt A. Freeze-fracture studies of cerebral endothelial tight junctions. Methods Mol Med. 2003;89:51-66.

76. DeStefano JG, et al. Real-time quantification of endothelial response to shear stress and vascular modulators. Integr Biol. 2017;9(4):362-74.

77. DeStefano JG, et al. Effect of shear stress on iPSC-derived human brain microvascular endothelial cells (dhBMECs). Fluids Barriers CNS 2017:14(1):20.

78. Cucullo L, et al. The role of shear stress in blood-brain barrier endothelial physiology. BMC Neurosci. 2011;12(1):40.

79. Garcia-Polite F, et al. Pulsatility and high shear stress deteriorate barrier phenotype in brain microvascular endothelium. J Cereb Blood Flow Metab. 2017;37(7):2614-25.

80. Reinitz A, et al. Human brain microvascular endothelial cells resist elongation due to shear stress. Microvasc Res. 2015;99:8-18.

81. Dolan JM, Kolega J, Meng H. High wall shear stress and spatial gradients in vascular pathology: a review. Ann Biomed Eng. 2013;41(7):1411-27.

82. Malek AM, Alper SL, Izumo S. Hemodynamic shear stress and its role in atherosclerosis. JAMA. 1999;282(21):2035-42

83. Ku DN. Blood flow in arteries. Annu Rev Fluid Mech. 1997:29(1):399-434.

84. Gould IG, et al. The capillary bed offers the largest hemodynamic resistance to the cortical blood supply. J Cereb Blood Flow Metab. 2017;37(1):52-68

85. Kleinfeld D, et al. Fluctuations and stimulus-induced changes in blood flow observed in individual capillaries in layers 2 through 4 of rat neocortex. Proc Natl Acad Sci. 1998;95(26):15741-6.

86. Lyons DG, et al. Mapping oxygen concentration in the awake mouse brain. Elife. 2016;5:e12024. 
87. Unekawa $M$, et al. RBC velocities in single capillaries of mouse and rat brains are the same, despite 10-fold difference in body size. Brain Res. 2010;1320:69-73.

88. Hudetz AG. Blood flow in the cerebral capillary network: a review emphasizing observations with intravital microscopy. Microcirculation. 1997;4(2):233-52.

89. Villringer $A$, et al. Capillary perfusion of the rat brain cortex. An in vivo confocal microscopy study. Circ Res. 1994;75(1):55-62.

90. Ivanov K, Kalinina M, Levkovich YI. Blood flow velocity in capillaries of brain and muscles and its physiological significance. Microvasc Res. 1981;22(2):143-55.

91. Ma Y, et al. On-line measurement of the dynamic velocity of erythrocytes in the cerebral microvessels in the rat. Microvasc Res. 1974;8(1):1-13.

92. Turitto VT. Blood viscosity, mass transport, and thrombogenesis. Prog Hemost Thromb. 1982;6:139-77.

93. Drake $\mathrm{CT}$, ladecola $\mathrm{C}$. The role of neuronal signaling in controlling cerebral blood flow. Brain Lang. 2007;102(2):141-52.

94. Girouard $\mathrm{H}$, ladecola C. Neurovascular coupling in the normal brain and in hypertension, stroke, and Alzheimer disease. J Appl Physiol. 2006;100(1):328-35

95. Lauritzen M. Relationship of spikes, synaptic activity, and local changes of cerebral blood flow. J Cereb Blood Flow Metab. 2001;21(12):1367-83.

96. Chen $\mathrm{BR}$, et al. A critical role for the vascular endothelium in functional neurovascular coupling in the brain. J Am Heart Assoc. 2014;3(3):e000787.

97. Chen BR, et al. High-speed vascular dynamics of the hemodynamic response. Neuroimage. 2011;54(2):1021-30.

98. Shih AY, et al. Two-photon microscopy as a tool to study blood flow and neurovascular coupling in the rodent brain. J Cereb Blood Flow Metab. 2012:32(7):1277-309.

99. Koutsiaris AG, et al. Volume flow and wall shear stress quantification in the human conjunctival capillaries and post-capillary venules in vivo. Biorheology. 2007;44(5-6):375-86.

100. Santisakultarm TP, et al. In vivo two-photon excited fluorescence microscopy reveals cardiac- and respiration-dependent pulsatile blood flow in cortical blood vessels in mice. Am J Physiol Heart Circ Physiol. 2012;302(7):H1367-77.

101. Errico C, et al. Ultrafast ultrasound localization microscopy for deep super-resolution vascular imaging. Nature. 2015;527(7579):499.

102. Gangoda SVS, et al. Pulsatile stretch as a novel modulator of amyloid precursor protein processing and associated inflammatory markers in human cerebral endothelial cells. Sci Rep. 2018;8(1):1689.

103. Ye $\mathrm{M}$, et al. Brain microvascular endothelial cells resist elongation due to curvature and shear stress. Sci Rep. 2014;4:4681.

104. Tilling T, et al. Expression and adhesive properties of basement membrane proteins in cerebral capillary endothelial cell cultures. Cell Tissue Res. 2002;310(1):19-29.

105. Tilling $T$, et al. Basement membrane proteins influence brain capillary endothelial barrier function in vitro. J Neurochem. 1998;71(3):1151-7.

106. Hartmann C, et al. The impact of glia-derived extracellular matrices on the barrier function of cerebral endothelial cells: an in vitro study. Exp Cell Res. 2007;313(7):1318-25.

107. Morrissey MA, Sherwood DR. An active role for basement membrane assembly and modification in tissue sculpting. J Cell Sci. 2015;128(9):1661-8

108. Iozzo RV, et al. The biology of perlecan: the multifaceted heparan sulphate proteoglycan of basement membranes and pericellular matrices. Biochem J. 1994;302(Pt 3):625

109. Thomsen MS, Routhe LJ, Moos T. The vascular basement membrane in the healthy and pathological brain. J Cereb Blood Flow Metab. 2017;37(10):3300-17.

110. Dermietzel R, Krause D. Molecular anatomy of the blood-brain-barrier as defined by immunocytochemistry. Int Rev Cytol. 1991;127:57-109.

111. Sykova E, Nicholson C. Diffusion in brain extracellular space. Physiol Rev. 2008:88(4):1277-340.

112. Kinney JP, et al. Extracellular sheets and tunnels modulate glutamate diffusion in hippocampal neuropil. J Comp Neurol. 2013;521(2):448-64.

113. Thorne RG, Nicholson C. In vivo diffusion analysis with quantum dots and dextrans predicts the width of brain extracellular space. Proc Natl Acad Sci USA. 2006:103(14):5567-72.
114. Thorne RG, Hrabetova S, Nicholson C. Diffusion measurements for drug design. Nat Mater. 2005;4(10):713.

115. Kroeger D, et al. Activity-dependent layer-specific changes in the extracellular chloride concentration and chloride driving force in the rat hippocampus. J Neurophysiol. 2010;103(4):1905-14

116. Zimmermann DR, Dours-Zimmermann MT. Extracellular matrix of the central nervous system: from neglect to challenge. Histochem Cell Biol. 2008;130(4):635-53.

117. Yamaguchi Y. Lecticans: organizers of the brain extracellular matrix. Cell Mol Life Sci. 2000;57(2):276-89.

118. Sanes JR. Extracellular-matrix molecules that influence neural development. Annu Rev Neurosci. 1989;12:491-516.

119. Luissint $A C$, et al. Tight junctions at the blood brain barrier: physiological architecture and disease-associated dysregulation. Fluids Barriers CNS. 2012;9(1):23.

120. Matter K, Balda MS. Signalling to and from tight junctions. Nat Rev Mol Cell Biol. 2003;4(3):225-36.

121. Morita K, et al. Endothelial claudin: claudin-5/TMVCF constitutes tight junction strands in endothelial cells. J Cell Biol. 1999;147(1):185-94.

122. Ohtsuki S, et al. mRNA expression levels of tight junction protein genes in mouse brain capillary endothelial cells highly purified by magnetic cell sorting. J Neurochem. 2008;104(1):147-54.

123. Weksler BB, et al. Blood-brain barrier-specific properties of a human adult brain endothelial cell line. FASEB J. 2005;19(13):1872-4.

124. Bernas MJ, et al. Establishment of primary cultures of human brain microvascular endothelial cells to provide an in vitro cellular model of the blood-brain barrier. Nat Protoc. 2010:5(7):1265-72.

125. Goodall EF, et al. Age-associated changes in the blood-brain barrier: comparative studies in human and mouse. Neuropathol Appl Neurobiol. 2018;44(3):328-40.

126. Errede $\mathrm{M}$, et al. The contribution of CXCL12-expressing radial glia cells to neuro-vascular patterning during human cerebral cortex development. Front Neurosci. 2014;8:324.

127. Gaillard PJ, de Boer AG. Relationship between permeability status of the blood-brain barrier and in vitro permeability coefficient of a drug. Eur J Pharm Sci. 2000;12(2):95-102.

128. Crone C, Olesen SP. Electrical resistance of brain microvascular endothelium. Brain Res. 1982;241(1):49-55.

129. Butt AM, Jones HC, Abbott NJ. Electrical resistance across the bloodbrain barrier in anaesthetized rats: a developmental study. J Physiol. 1990;429:47-62.

130. Butt AM, Jones HC. Effect of histamine and antagonists on electricalresistance across the blood-brain-barrier in rat brain-surface microvessels. Brain Res. 1992;569(1):100-5.

131. Smith QR, Rapoport SI. Cerebrovascular permeability coefficients to sodium, potassium, and chloride. J Neurochem. 1986;46(6):1732-42.

132. Eigenmann DE, et al. Comparative study of four immortalized human brain capillary endothelial cell lines, hCMEC/D3, hBMEC, TY10, and BB19, and optimization of culture conditions, for an in vitro bloodbrain barrier model for drug permeability studies. Fluids Barriers CNS. 2013;10(1):33.

133. Daniels BP, et al. Immortalized human cerebral microvascular endothelial cells maintain the properties of primary cells in an in vitro model of immune migration across the blood brain barrier. J Neurosci Methods. 2013;212(1):173-9.

134. Khan NA. Novel in vitro and in vivo models to study central nervous system infections due to Acanthamoeba spp. Exp Parasitol. 2010;126(1):69-72

135. Saunders NR, et al. The rights and wrongs of blood-brain barrier permeability studies: a walk through 100 years of history. Front Neurosci. 2014;8:404

136. Ribatti $D$, et al. Development of the blood-brain barrier: a historical point of view. Anat Rec B New Anat. 2006;289(1):3-8.

137. Easton AS, Sarker MH, Fraser PA. Two components of blood-brain barrier disruption in the rat. J Physiol. 1997;503(3):613-23.

138. Jeong JY, et al. Functional and developmental analysis of the bloodbrain barrier in zebrafish. Brain Res Bull. 2008;75(5):619-28.

139. Yuan W, et al. Non-invasive measurement of solute permeability in cerebral microvessels of the rat. Microvasc Res. 2009;77(2):166-73. 
140. Shi L, et al. Quantification of blood-brain barrier solute permeability and brain transport by multiphoton microscopy. J Biomech Eng. 2014;136(3):031005

141. Nag S. Blood-brain barrier permeability using tracers and immunohistochemistry. In: Nag S, editor. The blood-brain barrier: biological and research protocols. New York City: Humana Press; 2003. p. 133-44.

142. Honig G, et al. Blood-brain barrier deterioration and hippocampal gene expression in polymicrobial sepsis: an evaluation of endothelial MyD88 and the vagus nerve. PLoS ONE. 2016;11(1):e0144215.

143. Wulkersdorfer $B$, et al. Using positron emission tomography to study transporter-mediated drug-drug interactions in tissues. Clin Pharmacol Ther. 2014;96(2):206-13.

144. Dauchy S, et al. ABC transporters, cytochromes P450 and their main transcription factors: expression at the human blood-brain barrier. $J$ Neurochem. 2008;107(6):1518-28.

145. Ohtsuki S, Terasaki T. Contribution of carrier-mediated transport systems to the blood-brain barrier as a supporting and protect ing interface for the brain; Importance for CNS drug discovery and development. Pharm Res. 2007;24(9):1745-58.

146. Summerfield SG, et al. Central nervous system drug disposition: the relationship between in situ brain permeability and brain free fraction. J Pharmacol Exp Ther. 2007;322(1):205-13.

147. Bauer $M$, et al. Approaching complete inhibition of P-glycoprotein at the human blood-brain barrier: an (R)-[11C]verapamil PET study. J Cereb Blood Flow Metab. 2015;35(5):743-6.

148. Polli JW, et al. An unexpected synergist role of P-glycoprotein and breast cancer resistance protein on the central nervous system penetration of the tyrosine kinase inhibitor lapatinib ( $\mathrm{N}$-\{3-chloro-4[(3-fluorobenzyl)oxy]phenyl\}-6-[5-(\{[2-(methylsulfonyl)ethyl]amino\} methyl)-2-furyl]-4-quinazolinamine; GW572016). Drug Metab Dispos. 2009;37(2):439-42.

149. Hobson B, Denekamp J. Endothelial proliferation in tumours and normal tissues: continuous labelling studies. Br J Cancer. 1984;49(4):405-13.

150. Spaet TH, Lejnieks I. Mitotic activity of rabbit blood vessels. Proc Soc Exp Biol Med. 1967;125(4):1197-201.

151. Tannock IF, Hayashi S. The proliferation of capillary endothelial cells. Cancer Res. 1972;32(1):77-82.

152. Cudmore RH, Dougherty SE, Linden DJ. Cerebral vascular structure in the motor cortex of adult mice is stable and is not altered by voluntary exercise (vol 37, pg 3725, 2017). J Cereb Blood Flow Metab. 2017;37(12):3824.

153. Harb R, et al. In vivo imaging of cerebral microvascular plasticity from birth to death. J Cereb Blood Flow Metab. 2013;33(1):146-56.

154. Iadecola C, Nedergaard M. Glial regulation of the cerebral microvasculature. Nat Neurosci. 2007;10(11):1369-76.

155. Halassa MM, Haydon PG. Integrated brain circuits: astrocytic networks modulate neuronal activity and behavior. Annu Rev Physiol. 2010;72:335-55

156. Figley CR, Stroman PW. The role(s) of astrocytes and astrocyte activity in neurometabolism, neurovascular coupling, and the production of functional neuroimaging signals. Eur J Neurosci. 2011;33(4):577-88.

157. Abbott NJ, Ronnback L, Hansson E. Astrocyte-endothelial interactions at the blood-brain barrier. Nat Rev Neurosci. 2006;7(1):41-53.

158. Oberheim NA, et al. Uniquely hominid features of adult human astrocytes. J Neurosci. 2009;29(10):3276-87.

159. Mathiisen TM, et al. The perivascular astroglial sheath provides a complete covering of the brain microvessels: an electron microscopic 3D reconstruction. Glia. 2010;58(9):1094-103.

160. Ridet $\mathrm{J}$, et al. Reactive astrocytes: cellular and molecular cues to biological function. Trends Neurosci. 1997;20(12):570-7.

161. Pekny M, Nilsson M. Astrocyte activation and reactive gliosis. Glia. 2005;50(4):427-34.

162. Sofroniew MV. Molecular dissection of reactive astrogliosis and glial scar formation. Trends Neurosci. 2009:32(12):638-47.

163. Zamanian JL, et al. Genomic analysis of reactive astrogliosis. J Neurosci. 2012;32(18):6391-410.

164. Placone AL, Quinones-Hinojosa A, Searson PC. The role of astrocytes in the progression of brain cancer: complicating the picture of the tumor microenvironment. Tumour Biol. 2016:37(1):61-9.
165. Puschmann TB, et al. Bioactive 3D cell culture system minimizes cellular stress and maintains the in vivo-like morphological complexity of astroglial cells. Glia. 2013;61(3):432-40.

166. Wang DD, Bordey A. The astrocyte odyssey. Prog Neurobiol. 2008:86(4):342-67.

167. Wolburg H, Lippoldt A. Tight junctions of the blood-brain barrier: development, composition and regulation. Vasc Pharmacol. 2002;38(6):323-37.

168. Nicchia GP, et al. The role of aquaporin-4 in the blood-brain barrier development and integrity: studies in animal and cell culture models. Neuroscience. 2004;129(4):935-45.

169. Levy AF, et al. Influence of basement membrane proteins and endothelial cell-derived factors on the morphology of human fetal-derived astrocytes in 2D. PLoS ONE. 2014;9(3):e92165.

170. Placone $\mathrm{AL}$, et al. Human astrocytes develop physiological morphology and remain quiescent in a novel 3D matrix. Biomaterials. 2015;42:134-43.

171. Armulik A, Genove G, Betsholtz C. Pericytes: developmental, physiological, and pathological perspectives, problems, and promises. Dev Cell. 2011:21(2):193-215

172. Hartmann DA, et al. Pericyte structure and distribution in the cerebral cortex revealed by high-resolution imaging of transgenic mice. Neurophotonics. 2015;2(4):041402.

173. Hill RA, et al. Regional blood flow in the normal and ischemic brain is controlled by arteriolar smooth muscle cell contractility and not by capillary pericytes. Neuron. 2015;87(1):95-110.

174. Damisah EC, et al. A fluoro-Nissl dye identifies pericytes as distinct vascular mural cells during in vivo brain imaging. Nat Neurosci. 2017;20(7):p. 1023-+.

175. Winkler EA, Bell RD, Zlokovic BV. Central nervous system pericytes in health and disease. Nat Neurosci. 2011;14(11):1398-405.

176. Sweeney MD, Ayyadurai S, Zlokovic BV. Pericytes of the neurovascular unit: key functions and signaling pathways. Nat Neurosci. 2016;19(6):771-83.

177. Frank RN, Dutta S, Mancini MA. Pericyte coverage is greater in the retinal than in the cerebral capillaries of the rat. Invest Ophthalmol Vis Sci. 1987;28(7):1086-91.

178. Attwell D, et al. What is a pericyte? J Cereb Blood Flow Metab. 2016;36(2):451-5

179. Hall CN, et al. Capillary pericytes regulate cerebral blood flow in health and disease. Nature. 2014;508(7494):55-60.

180. Crisan $\mathrm{M}$, et al. A perivascular origin for mesenchymal stem cells in multiple human organs. Cell Stem Cell. 2008;3(3):301-13.

181. Dore-Duffy P. Pericytes: pluripotent cells of the blood brain barrier. Curr Pharm Des. 2008;14(16):1581-93.

182. Correa D, et al. Mesenchymal stem cells regulate melanoma cancer cells extravasation to bone and liver at their perivascular niche. Int J Cancer. 2016;138(2):417-27.

183. Blocki $A$, et al. Not all MSCs can act as pericytes: functional in vitro assays to distinguish pericytes from other mesenchymal stem cells in angiogenesis. Stem Cells Dev. 2013;22(17):2347-55.

184. Guimaraes-Camboa N, et al. Pericytes of multiple organs do not behave as mesenchymal stem cells in vivo. Cell Stem Cell. 2017;20(3):345-359 e5.

185. Gerhardt $\mathrm{H}$, Betsholtz C. Endothelial-pericyte interactions in angiogenesis. Cell Tissue Res. 2003;314(1):15-23.

186. Kim J, et al. Engineering of a biomimetic pericyte-covered 3D microvascular network. PLoS ONE. 2015;10(7):e0133880.

187. Daneman $\mathrm{R}$, et al. Pericytes are required for blood-brain barrier integrity during embryogenesis. Nature. 2010:468(7323):562-6.

188. Hayashi K, et al. Effects of hypoxia on endothelial/pericytic co-culture model of the blood-brain barrier. Regul Pept. 2004;123(1):77-83.

189. Nakagawa S, et al. A new blood-brain barrier model using primary rat brain endothelial cells, pericytes and astrocytes. Neurochem Int. 2009;54(3-4):253-63.

190. Nakagawa S, et al. Pericytes from brain microvessels strengthen the barrier integrity in primary cultures of rat brain endothelial cells. Cell Mol Neurobiol. 2007;27(6):687-94.

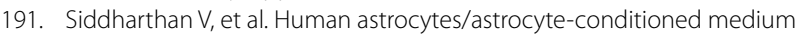
and shear stress enhance the barrier properties of human brain microvascular endothelial cells. Brain Res. 2007:1147:39-50. 
192. Thomsen LB, Burkhart A, Moos T. A triple culture model of the bloodbrain barrier using porcine brain endothelial cells, astrocytes and pericytes. PLoS ONE. 2015;10(8):e0134765.

193. Malina KCK, Cooper I, Teichberg VI. Closing the gap between the in vivo and in vitro blood-brain barrier tightness. Brain Res. 2009;1284:12-21.

194. Yang T, Roder KE, Abbruscato TJ. Evaluation of bEnd5 cell line as an in vitro model for the blood-brain barrier under normal and hypoxic/ aglycemic conditions. J Pharm Sci. 2007;96(12):3196-213.

195. Hatherell K, et al. Development of a three-dimensional, all-human in vitro model of the blood-brain barrier using mono-, CO-, and tricultivation transwell models. J Neurosci Methods. 2011;199(2):223-9.

196. Hori S, et al. A pericyte-derived angiopoietin-1 multimeric complex induces occludin gene expression in brain capillary endothelial cells through Tie-2 activation in vitro. J Neurochem. 2004;89(2):503-13.

197. Weksler BB, et al. Blood-brain barrier-specific properties of a human adult brain endothelial cell line. FASEB J. 2005;19(11):1872-4.

198. Thanabalasundaram $\mathrm{G}$, et al. Regulation of the blood-brain barrier integrity by pericytes via matrix metalloproteinases mediated activation of vascular endothelial growth factor in vitro. Brain Res. 2010;1347:1-10.

199. Thanabalasundaram $\mathrm{G}$, et al. The impact of pericytes on the bloodbrain barrier integrity depends critically on the pericyte differentiation stage. Int J Biochem Cell Biol. 2011;43(9):1284-93.
200. Lippmann ES, et al. Blood-brain barrier modeling with co-cultured neural progenitor cell-derived astrocytes and neurons. J Neurochem. 2011;119(3):507-20.

201. Thomsen LB, Burkhart A, Moos T. A triple culture model of the bloodbrain barrier using porcine brain endothelial cells, astrocytes and pericytes. PLoS ONE. 2015;10(8):1-16.

202. Roberts B, et al. Systematic gene tagging using CRISPR/Cas9 in human stem cells to illuminate cell organization. Mol Biol Cell. 2017:28(21):2854-74.

203. Vanlandewijck M, et al. A molecular atlas of cell types and zonation in the brain vasculature. Nature. 2018;554(7693):475-80.

204. Linville RM, et al. Physical and chemical signals that promote vascularization of capillary-scale channels. Cell Mol Bioeng. 2016;9(1):73-84.

205. Maoz BM, et al. A linked organ-on-chip model of the human neurovascular unit reveals the metabolic coupling of endothelial and neuronal cells. Nat Biotechnol. 2018;36(9):865-74.

206. Park J, et al. A 3D human triculture system modeling neurodegeneration and neuroinflammation in Alzheimer's disease. Nat Neurosci. 2018;21(7):941-51.
Ready to submit your research? Choose BMC and benefit from:

- fast, convenient online submission

- thorough peer review by experienced researchers in your field

- rapid publication on acceptance

- support for research data, including large and complex data types

- gold Open Access which fosters wider collaboration and increased citations

- maximum visibility for your research: over $100 \mathrm{M}$ website views per year

At BMC, research is always in progress.

Learn more biomedcentral.com/submissions 